\title{
Suppression of Hiwi inhibits the growth and epithelial-mesenchymal transition of cervical cancer cells
}

\author{
GUANGJUN PEI ${ }^{1}$, BAOJIAN LI $^{2}$ and ANJUN MA ${ }^{3}$ \\ ${ }^{1}$ Department of Radiotherapy, The First Hospital of Lanzhou University, Lanzhou, Gansu 730000; ${ }^{2}$ Department of Oncology, \\ Zaozhuang Mining Group Center Hospital, Zaozhuang, Shandong 277800; ${ }^{3}$ Department of Gynecology, \\ The Second People's Hospital of Liaocheng, Linqing, Shandong 252600, P.R. China
}

Received October 24, 2016; Accepted September 28, 2017

DOI: $10.3892 / 01.2018 .9056$

\begin{abstract}
Cervical cancer is a common gynecological malignancy. Hiwi exhibits a high level of expression in cervical cancer cells. However, the effects of Hiwi expression in cervical cancer cells remain unresolved. In the present study, the effects of Hiwi downregulation on the growth and epithelial-mesenchymal transition of cervical cancer cells were investigated. The results of the present study revealed that the suppression of Hiwi was able to inhibit the proliferation of cervical cancer cells and arrest cell cycle at G1 phase. The downregulation of Hiwi was also revealed to inhibit the epithelial-mesenchymal transition process of cervical cancer cells by regulating the expression of E-cadherin, $\mathrm{N}$-cadherin, vimentin, and snail. The present study demonstrated that the suppression of Hiwi was able to inhibit the growth and epithelial-mesenchymal transition of cervical cancer cells. Therefore, the results suggest that Hiwi may function as an oncogene in cervical cancer cells and may become a potential target for cervical cancer therapy.
\end{abstract}

\section{Introduction}

Cervical cancer is one of the most common malignancies globally and is one of the leading causes of mortality resulting from gynecologic malignancies (1). In recent years, the incidence of cervical cancer has decreased. However, the rate of cervical cancer-associated morbidity in young adult women has increased.

Correspondence to: Dr Anjun Ma, Department of Gynecology, The Second People's Hospital of Liaocheng, 306 Jiankang Road, Linqing, Shandong 252600, P.R. China

E-mail: anjun_gynecology@163.com

Abbreviations: PCR, polymerase chain reaction; PCNA, proliferating cell nuclear antigen; TBST, Tris-buffered saline with Tween-20; DMEM, Dulbecco's modified Eagle's medium; FBS, fetal bovine serum; EMT, epithelial-mesenchymal transition

Key words: Hiwi, cervical cancer, proliferation, cell cycle, epithelial-mesenchymal transition
The members of the Piwi protein family are highly conserved during evolution and serve notable roles in cell proliferation, gametogenesis, germ cell proliferation and translational regulation (2-4). Hiwi is a human homologue of the Piwi family, located on chromosome 12q24.33 and encoding a $98.5 \mathrm{kDa}$ protein. Hiwi is expressed in $\mathrm{CD} 34^{+}$hematopoietic stem cells, but not in well-differentiated cell populations (5). Hiwi serves a function in the development of hematopoietic stem cells (5). Prior studies have demonstrated that Hiwi is also expressed in various types of cancer cells and affects the differentiation and proliferation of tumor cells (2,6-11). Overexpression of Hiwi is reported to lead to tumors (11).

Hiwi exhibits an increased level of expression in cervical cancer cells $(12,13)$. However, the function of Hiwi in cervical cancer cells remains unclear. In the present study, the effects of siRNA induced-knockdown of Hiwi on the growth and epithelial-mesenchymal transition of cervical cancer cells were investigated. The present study reveals that Hiwi may act as an oncogene in cervical cancer cells and may therefore be a novel target for the treatment of cervical cancer.

\section{Materials and methods}

Cell culture. Human cervical cancer cells, HeLa, were obtained from the American Type Culture Collection (Manassas, VA, USA). The cells were grown in Dulbecco's modified Eagle's medium (DMEM; Gibco; Thermo Fisher Scientific, Inc., Waltham, MA, USA) supplemented with $10 \%$ fetal bovine serum (FBS; Gibco; Thermo Fisher Scientific, Inc.) and cultured in a humidified atmosphere at $37^{\circ} \mathrm{C}$ with $5 \% \mathrm{CO}_{2}$.

Transfection. Hiwi specific small interfering RNA (siRNA) (sequence, 5'-GCCGUUCAUACA AGACUAATT-3' and 5'-UUAGUCUUGUAUGAACGGCTT-3') and a scrambled negative control (sequence, 5'-UUCUCCGAACGUGUC ACGUTT-3' and 5'-ACGUGACACGUUCGGAGAATT-3') were obtained from Biomics Biotechnologies Co., Ltd. (Nantong, China). The cells were seeded into 6-well plates ( $1 \times 10^{5}$ cells/well). After $24 \mathrm{~h}$, the cell medium was changed to serum-free medium for an additional $6 \mathrm{~h}$. Then $100 \mathrm{pmol}$ siRNA or its corresponding negative control was transfected into the cells using Lipofectamine 2000 reagent (Invitrogen; Thermo Fisher Scientific, Inc.) according to the manufacturer's 
protocol. At $6 \mathrm{~h}$ post-transfection, the cell medium was changed to fresh DMEM supplemented with $10 \%$ FBS. After culturing at $37^{\circ} \mathrm{C}$ for additional $48 \mathrm{~h}$, the cells in each group were collected for subsequent experiments.

Reverse transcription-quantitative polymerase chain reaction (RT-qPCR). Total RNA was extracted from cells of each group using TRIzol reagent (Invitrogen; Thermo Fisher Scientific, Inc.) according to the manufacturer's protocol. The total RNA was reverse transcribed to cDNA using Moloney murine leukemia virus reverse transcriptase (Promega Corporation, Madison, WI, USA). Then the level of Hiwi mRNA was measured using RT-qPCR with the cDNA as the template and primers as follows: Hiwi forward, 5'-ATGGCCATCTAC AAGCAGTC-3' and reverse, 5'-GACAGTGCTCGCTTA GTGC-3'; and GAPDH forward, 5'-CACCCACTCCTCCAC CTTTG-3' and reverse, 5'-CCACCACCCTGTTGCTGTAG-3'. The qPCR was performed on a StepOne PCR system (Applied Biosystems; Thermo Fisher Scientific, Inc.). The thermocycling conditions were as follows: $95^{\circ} \mathrm{C}$ for $10 \mathrm{~min}$; 40 cycles of $95^{\circ} \mathrm{C}$ for $10 \mathrm{sec}, 60^{\circ} \mathrm{C}$ for $30 \mathrm{sec}, 72^{\circ} \mathrm{C}$ for $30 \mathrm{sec}$; and then kept at $4^{\circ} \mathrm{C}$ for $10 \mathrm{~min}$. SYBR-Green reagent was obtained from Biomics Biotechnologies Co., Ltd. The level of Hiwi mRNA was normalized to GAPDH, and the relative mRNA level of Hiwi was calculated using the $2^{-\Delta \Delta \mathrm{Cq}}$ method (14).

Western blot analysis. The cells transfected with negative control or siRNA were harvested and proteins in cells were extracted on ice using radioimmunoprecipitation assay lysis buffer. The concentration of the proteins was measured using a Enhanced BCA Protein Assay kit (Beyotime Institute of Biotechnology, Haimen, China). $40 \mu$ g proteins were separated using $12 \%$ SDS-PAGE and transferred onto polyvinylidene fluoride membranes (EMD Millipore, Billerica, MA, USA). Following blocking with $5 \%$ skimmed milk at $37^{\circ} \mathrm{C}$ for $1 \mathrm{~h}$, the membranes were incubated with primary antibodies against Hiwi (1:1,000; cat. no. sc-22685; Santa Cruz Biotechnology, Inc., Dallas, TX, USA), proliferating cell nuclear antigen (PCNA; 1:2,000; cat. no. sc-25280; Santa Cruz Biotechnology, Inc.), cyclin A (1:1,000; cat. no. sc-751; Santa Cruz Biotechnology, Inc.), cyclin D1 (1:1,000; cat. no. sc-70899; Santa Cruz Biotechnology, Inc.), E-cadherin (1:1,000; cat. no. sc-71009; Santa Cruz Biotechnology, Inc.), N-cadherin (1:1,000; cat. no. sc-59987; Santa Cruz Biotechnology, Inc.), vimentin (1:1,000; cat. no. sc-5565; Santa Cruz Biotechnology, Inc.), snail family transcriptional repressor 1 (SNAIL; 1:1,000; cat. no. sc-28199; Santa Cruz Biotechnology, Inc.) and $\beta$-actin (1:2,000; cat. no. sc-130065; Santa Cruz Biotechnology, Inc.) at $4^{\circ} \mathrm{C}$ overnight. Following washing with Tris-buffered saline with Tween-20 (TBST), the membranes were incubated with corresponding horseradish peroxidase (HRP)-labeled goat anti-rabbit IgG (H+L) (cat. no. A0208), HRP-labeled goat anti-mouse IgG (H+L) (cat.no. A0216), or HRP-labeled donkey anti-goat $\operatorname{IgG}(\mathrm{H}+\mathrm{L})$ (cat. no. A0181) (1:5,000; Beyotime Institute of Biotechnology) at $37^{\circ} \mathrm{C}$ for $1 \mathrm{~h}$. Following washing with TBST, the targeted proteins were visualized using an Chemiluminescent HRP substrate (ECL) (EMD Millipore). The relative protein level was analyzed by Quantity One 4.6 (Bio-Rad, Hercules, CA, USA) and calculated as targeted protein level/reference protein level.
MTT assay. Following transfection, the cells $\left(3 \times 10^{3}\right.$ cells/well) were seeded into 96-wells plates. The cell viability was measured using MTT assay. Briefly, MTT at a final concentration of $0.5 \mathrm{mg} / \mathrm{ml}$ was added into the cells in each group at $4,12,24,36$ and $48 \mathrm{~h}$ and cultured at $37^{\circ} \mathrm{C}$ for an additional $4 \mathrm{~h}$. The supernatant was removed, and $200 \mu \mathrm{l}$ dimethyl sulfoxide (Sigma-Aldrich; Merck KGaA, Darmstadt, Germany) was added into each well. The absorbance at $490 \mathrm{~nm}$ was measured with a microplate reader.

Cell cycle detection. The cells were transfectged with neative control or siRNA, and cell cycle of the cells in each group was evaluated using flow cytometry at $48 \mathrm{~h}$ with a Cell Cycle and Apoptosis Analysis kit (Beyotime Institute of Biotechnology). Briefly, the cells in each group were collected, washed with ice-cold phosphate-buffered saline (PBS) and fixed with ice-cold $70 \%$ ethanol at $4^{\circ} \mathrm{C}$ overnight. Following washing with ice-cold PBS, the cells were resuspended in $500 \mu \mathrm{l}$ binding buffer and then $25 \mu \mathrm{l}$ propidium iodide and $10 \mu \mathrm{l}$ RNaseA were added into cells in each group. The cells were incubated at $37^{\circ} \mathrm{C}$ for $30 \mathrm{~min}$ and then analyzed using a flow cytometer (BD Biosciences, Franklin Lakes, NJ, USA).

Transwell assay. Following transfection with Hiwi siRNA or negative control, the cells were collected and suspended ( $1 \times 10^{5}$ cells $\left./ \mathrm{ml}\right)$. The Transwell inserts (Corning Life Sciences, Tewksbury, MA, USA) were inserted into a 24-well plate. Subsequently, $200 \mu \mathrm{l}$ cell suspension was added into the upper chambers, and $600 \mu \mathrm{l}$ DMEM containing 20\% FBS was added into the lower chambers. The cells were allowed to migrate at $37^{\circ} \mathrm{C}$ for $24 \mathrm{~h}$. Subsequently, the cells above the membranes were removed with cotton swabs. The cells below the membranes were fixed with $4 \%$ paraformaldehyde and stained with $0.5 \%$ crystal violet at room temperature for $15 \mathrm{~min}$. The cells were observed via light microscopy using a x200 magnification. The cells in each field of view were counted, and the average number of cells in five randomly selected fields of view was calculated as the number of migratory cells.

Statistical analysis. The results are presented as the mean \pm standard deviation. Differences between groups were analyzed using Student's t-test. $\mathrm{P}<0.05$ was considered to indicate a statistically significant difference.

\section{Results}

Hiwi siRNA decreases the level of Hiwi in cervical cancer cells. Hiwi siRNA was used to investigate the effects of Hiwi on cervical cancer cells. Following transfection with Hiwi siRNA or the negative control, the relative level of Hiwi mRNA was detected using RT-qPCR. The results revealed that the relative level of Hiwi mRNA was decreased to $11.01 \pm 4.78 \%$ following transfection with Hiwi siRNA (Fig. 1A). Western blot analysis demonstrated similar results to RT-qPCR. Compared with the control group, the relative protein level of Hiwi was decreased from $1.64 \pm 0.28$ to $0.33 \pm 0.09$ following transfection with Hiwi siRNA (Fig. 1B and C). These results demonstrated that Hiwi siRNA was able to effectively decrease the levels of mRNA and protein in cervical cancer cells. 


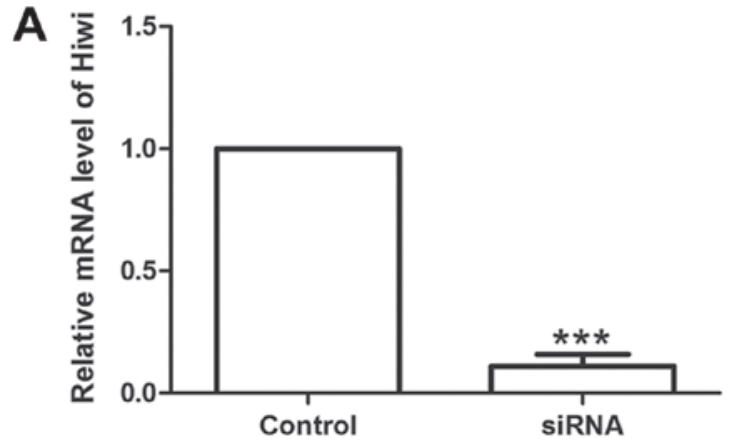

B
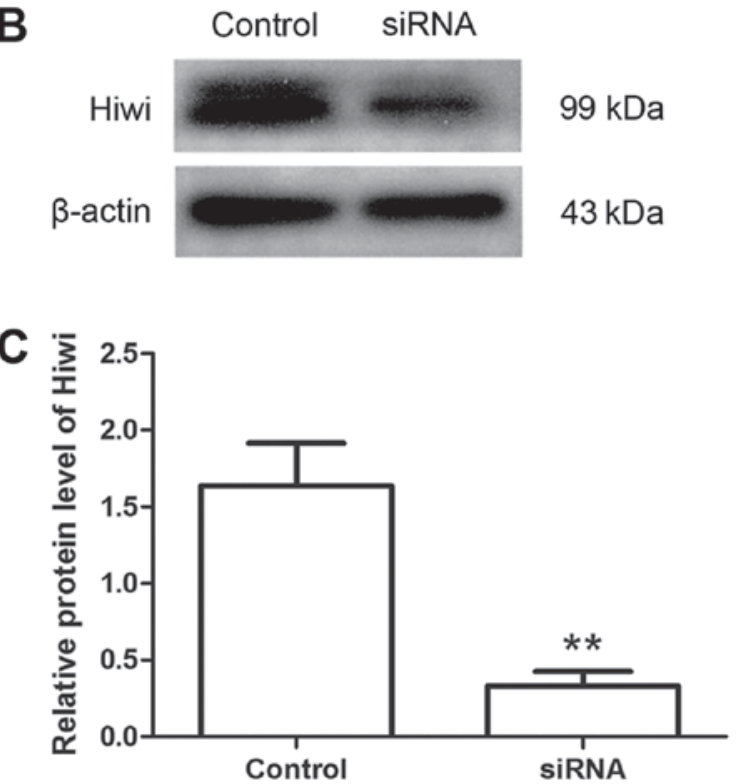

Figure 1. Hiwi siRNA decreases the levels of mRNA and protein in cervical cancer cells. (A) The level of Hiwi mRNA in cervical cancer cells was analyzed using reverse transcription-quantitative polymerase chain reaction. The relative level of Hiwi mRNA was normalized to GAPDH. (B) The level of Hiwi protein in cervical cancer cells was detected using western blotting with $\beta$-actin as the internal reference. (C) The relative level of Hiwi protein in each group was calculated. All experiments were repeated three times, and the results are presented as the mean \pm standard deviation. ${ }^{* *} \mathrm{P}<0.01$ vs. control cells. ${ }^{* * *} \mathrm{P}<0.001$ vs. control cells. siRNA, small interfering RNA.

Downregulation of Hiwi inhibits the proliferation of cervical cancer cells. Following transfection with Hiwi siRNA or the negative control, the proliferation of cervical cancer cells was detected using MTT assay. As presented in Fig. 2A, compared with the control group, the proliferation of the cells was significantly inhibited by transfection with Hiwi siRNA. The level of PCNA protein was detected by western blotting. The results of western blot analysis revealed that, following transfection with Hiwi siRNA, the relative level of PCNA protein was decreased from $1.30 \pm 0.178$ to $0.49 \pm 0.06$ (Fig. $2 \mathrm{~B}$ and C). These results support the hypothesis that transfection with Hiwi siRNA inhibits the proliferation of cervical cancer cells.

Downregulation of Hiwi inhibits the cell cycle of cervical cancer cells. The cell cycle has an important function in the growth of cancer cells, thus the effects of Hiwi siRNA on the cell cycle of cervical cancer cells were investigated using flow cytometry. The results of flow cytometry revealed that following transfection with Hiwi siRNA, the percentage
A

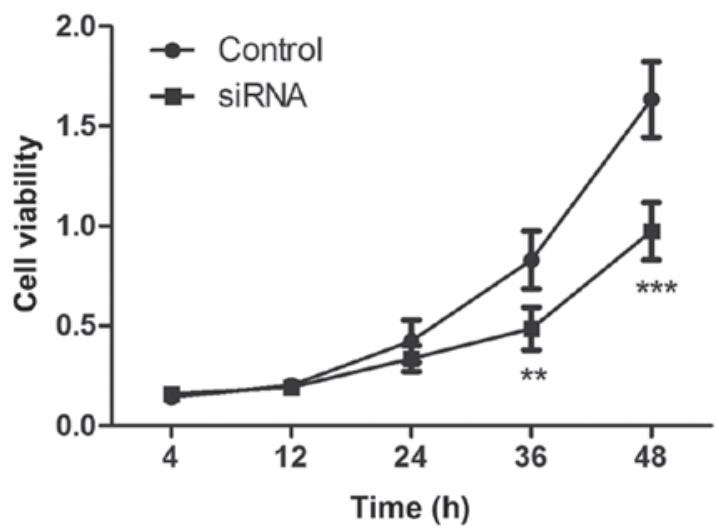

B
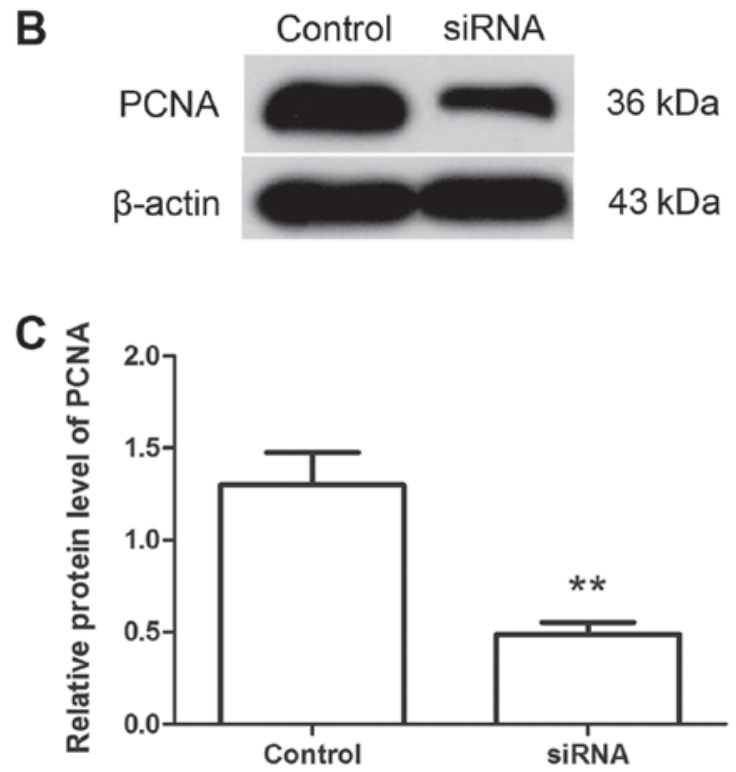

Figure 2. Downregulation of Hiwi inhibits the proliferation of cervical cancer cells. (A) The viability of cervical cancer cells was detected using MTT assay following transfection with Hiwi siRNA or negative control. (B) The level of PCNA protein in cervical cancer cells was detected using western blotting following transfection. $\beta$-actin was used as the internal reference. (C) The relative level of PCNA protein in each group was calculated. All experiments were repeated three times, and the results are presented as the mean \pm standard deviation. ${ }^{* *} \mathrm{P}<0.01,{ }^{* * *} \mathrm{P}<0.001$ vs. control cells. siRNA, small interfering RNA; PCNA, proliferating cell nuclear antigen.

of cells in the $\mathrm{G} 1$ phase was increased from $53.37 \pm 2.87$ to $64.78 \pm 3.49 \%$ (Fig. 3A and B). The levels of cyclin A and cyclin D1 proteins, which are important cytokines regulating the cell cycle progress, were also detected using western blotting. Western blot analysis revealed that following transfection with Hiwi siRNA, the relative level of cyclin A protein was decreased from $0.66 \pm 0.16$ to $0.17 \pm 0.03$ (Fig. $3 \mathrm{C}$ and D). The relative level of cyclin D1 protein was also decreased from $0.77 \pm 0.15$ to $0.12 \pm 0.02$ (Fig. $3 \mathrm{E}$ and $\mathrm{F}$ ). These results demonstrated that Hiwi siRNA may have an inhibitory effect on the cell cycle of cervical cancer cells.

Hiwi siRNA inhibits the epithelial-mesenchymal transition of cervical cancer cells. Following transfection with Hiwi siRNA, the migration of cervical cancer cells was evaluated using Transwell assay. The results of the Transwell assay identified that the number of migratory cells was decreased 


\section{A}
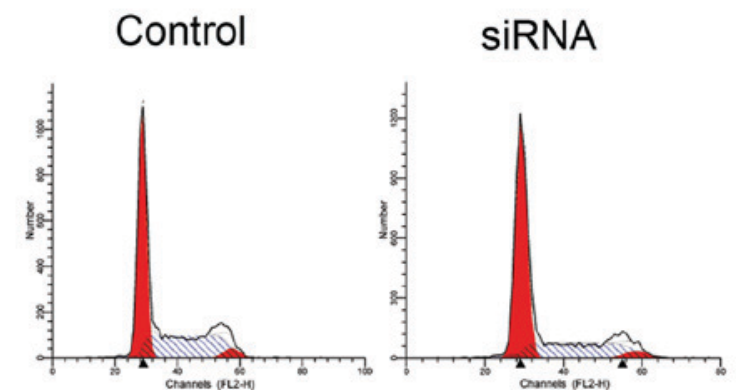

C

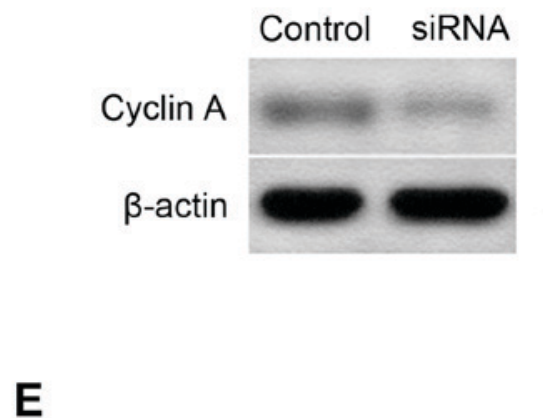

E

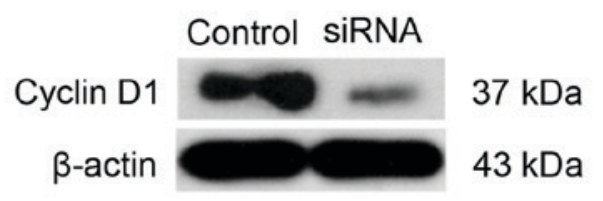

B

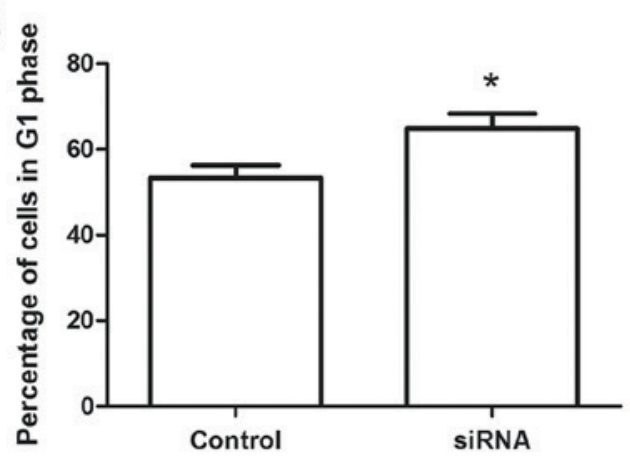

D \&

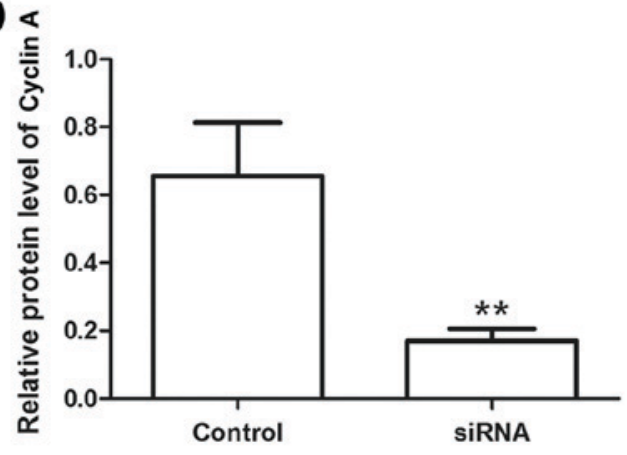

$F$ -

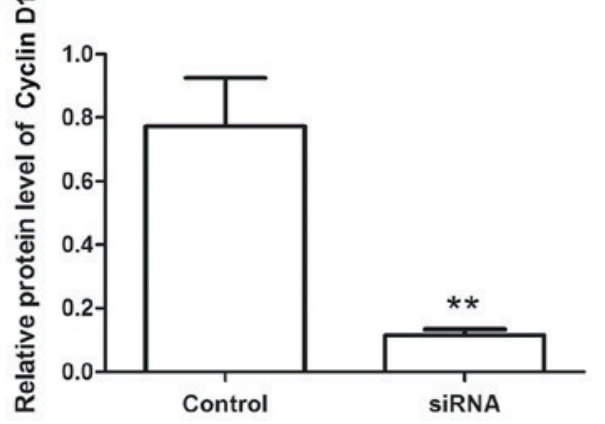

Figure 3. Downregulation of Hiwi arrests the cell cycle in cervical cancer cells. (A) The cell cycle of cervical cancer cells was detected using flow cytometry. (B) The percentage of cells in the G1 phase was calculated. (C) The level of cyclin A protein was detected using western blotting. (D) The relative level of cyclin A protein in each group was calculated. (E) The protein level of cyclin D1 was detected using western blotting. (F) The relative level of cyclin D1 protein in each group was calculated. All experiments were repeated three times, and the results are presented as the mean \pm standard deviation. ${ }^{*} \mathrm{P}<0.05,{ }^{* *} \mathrm{P}<0.01$ vs. control cells. siRNA, small interfering RNA.
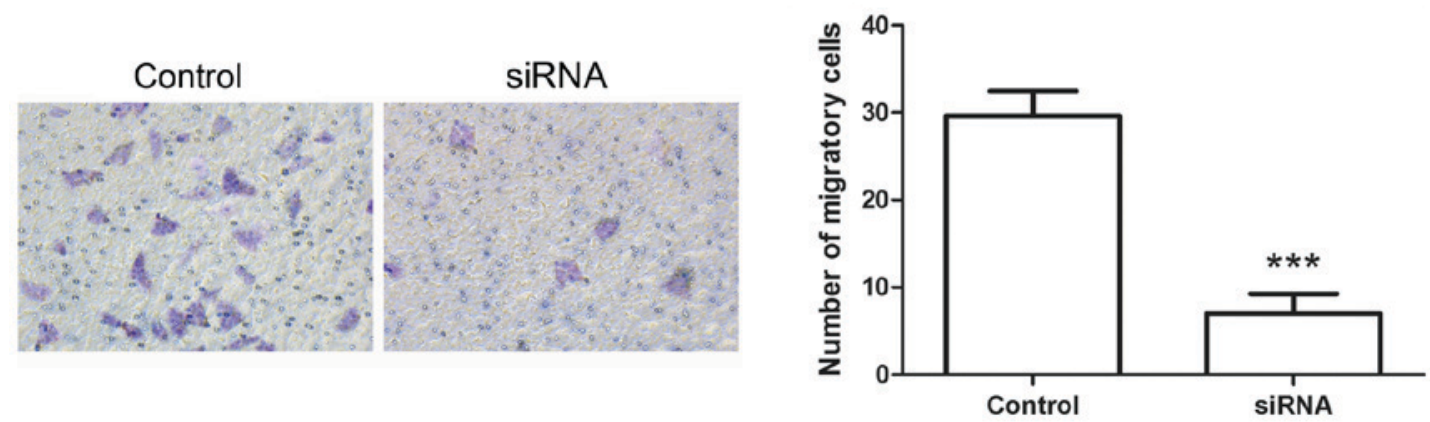

Figure 4. Downregulation of Hiwi inhibits the migration of cervical cancer cells. Transwell assay was performed to evaluate the changes in the migratory capability of cervical cancer cells. The cells were visualized using an optical microscope at a magnification of $x 200 .{ }^{* * *} \mathrm{P}<0.001$ vs. control cells. siRNA, small interfering RNA.

significantly in cells transfected with Hiwi siRNA compared with the control cells (Fig. 4A and B). The levels of E-cadherin, $\mathrm{N}$-cadherin, vimentin and snail proteins were detected using western blotting. The results of western blotting revealed that following transfection with Hiwi siRNA, the relative level of E-cadherin protein was increased from $0.22 \pm 0.05$ to $0.84 \pm 0.17$ (Fig. 5A and B). However the relative level of $\mathrm{N}$-cadherin protein was decreased from $0.96 \pm 0.14$ to $0.17 \pm 0.03$ (Fig. 5C and D). 
A

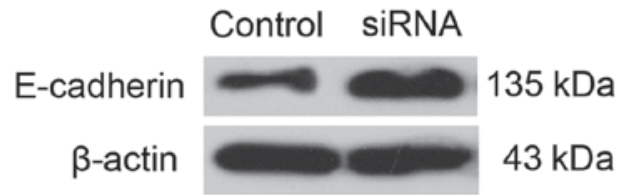

Control siRNA

$\mathrm{N}$-cadherin

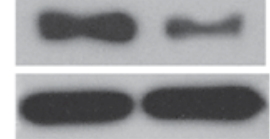

$130 \mathrm{kDa}$

$\beta$-actin

$43 \mathrm{kDa}$

$\mathbf{E}$

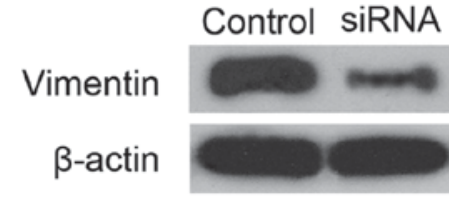

$57 \mathrm{kDa}$

$43 \mathrm{kDa}$
B

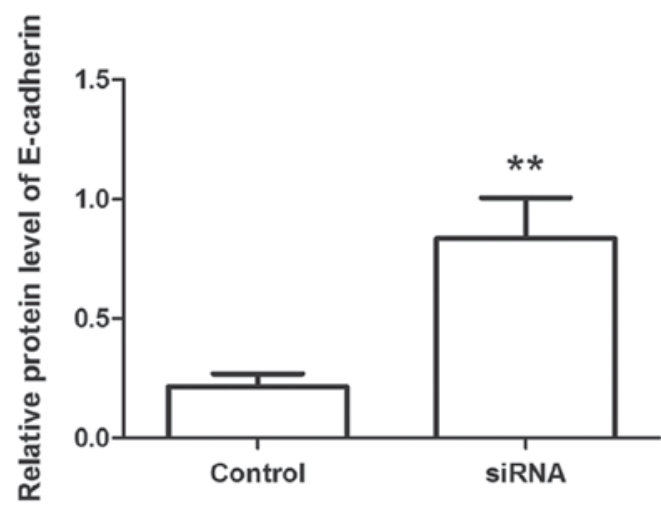

D

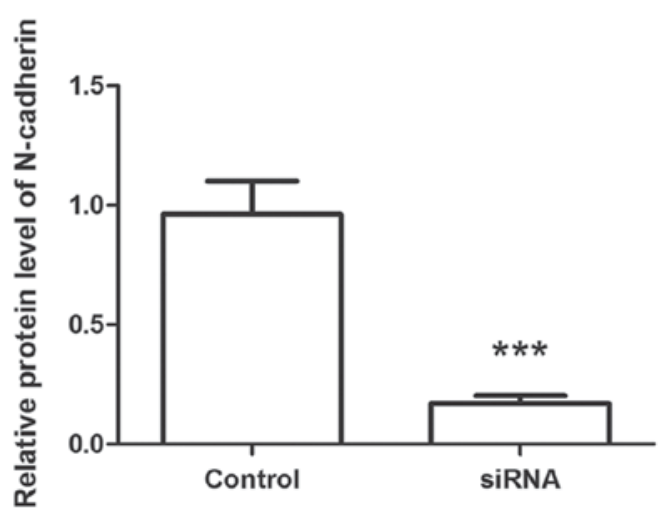

$\mathbf{F}$
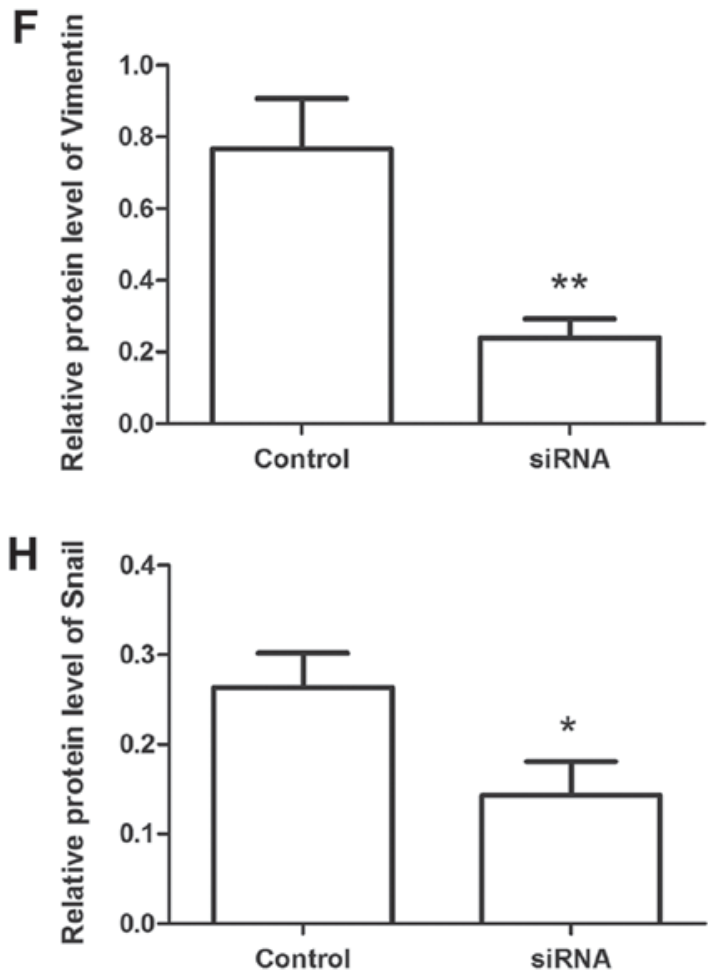

Figure 5. Downregulation of Hiwi increases the level of E-cadherin and decreases the levels of N-cadherin, vimentin and snail. (A) The level of E-cadherin protein was detected using western blotting. (B) The relative level of E-cadherin protein was calculated using $\beta$-actin as the internal reference. (C) Western blotting was used to detect the protein level of $\mathrm{N}$-cadherin. (D) The relative expression level of $\mathrm{N}$-cadherin was calculated using $\beta$-actin as the internal reference. (E) The protein level of vimentin was detected by western blotting. (F) The relative level of vimentin protein was calculated using $\beta$-actin as an internal reference. $(\mathrm{G})$ Western blotting was used to detect the level of snail protein. $(\mathrm{H})$ The relative level of snail protein was calculated using $\beta$-actin as the internal reference. All experiments were repeated three times, and the results are presented as the mean \pm standard deviation. ${ }^{*} \mathrm{P}<0.05$ vs. control cells. ${ }^{* *} \mathrm{P}<0.01$, ${ }^{* * * *} \mathrm{P}<0.001$ vs. control cells. siRNA, small interfering RNA; SNAIL, zinc finger protein SNAI1.

The relative level of vimentin protein was decreased from $0.77 \pm 0.14$ to $0.24 \pm 0.05$ (Fig. 5E and F), and the relative level of snail protein was decreased from $0.26 \pm 0.04$ to $0.14 \pm 0.04$

(Fig. $5 \mathrm{G}$ and $\mathrm{H}$ ). These results indicate the inhibitory effects of 
Hiwi siRNA on epithelial-mesenchymal transition of cervical cancer cells.

\section{Discussion}

In the present study, the effects of downregulating Hiwi in cervical cancer cells were investigated. The results of the present study demonstrated that suppression of Hiwi was able to inhibit the proliferation of cervical cancer cells and arrest cell cycle at the G1 phase. The downregulation of Hiwi was also able to inhibit the epithelial-mesenchymal transition process. Taken together, these results suggest that Hiwi may be a potential target for cervical cancer therapy.

Hiwi is overexpressed in various types of cancer, including colon $(15,16)$, liver (17), stomach (2) and pancreatic cancer (7), and is associated with the growth, migration and angiogenesis of cancer cells $(11,18)$. Hiwi contributes to tumorigenesis, serves as a potential biomarker of certain types of cancer (17) and is regarded to be an indicator of poor prognosis $(2,6-8,19)$. Previous studies have demonstrated that the expression of Hiwi is associated with the histological grade of cancer, however associations with age, gender, tumor size or location were not observed $(10,17)$. Additionally, Hiwi was revealed to be highly expressed in cervical cancer tissues $(12,13)$, which indicates that Hiwi may exhibit an association with cervical cancer progression. The results of the present study demonstrated that the downregulation of Hiwi was able to inhibit the growth and epithelial-mesenchymal transition of cervical cancer cells. These data indicate that Hiwi may serve an oncogenic function in cervical cancer cells. However, the present study was performed in only one cervical cancer cell line, which is a limitation of the study. Additional in vitro and in vivo experiments are required to further strengthen the findings of the present study.

Liu et al (12) demonstrated that Hiwi may be involved in cervical cancer carcinogenesis and may be a potential therapeutic target for the treatment of cervical cancer. Liu et al (12) demonstrated that the expression of Hiwi was associated with the stage of cervical cancer, but exhibited no association with the other clinical characteristics. Furthermore, another study (2) also demonstrated that by blocking endogenous Hiwi expression, it was able to inhibit the proliferation of gastric cancer cells. Liang et al (11) demonstrated that the proliferation of lung cancer cells was inhibited by downregulating Hiwi.

In the present study, the effects of silencing Hiwi on the growth of cervical cancer cells were investigated. The results revealed that the proliferation of cervical cancer cells was inhibited by transfection with Hiwi siRNA, with decreased levels of PCNA following transfection. Consistently, Liu et al (12) demonstrated that Hiwi promoted tumorigenicity of cervical cancer in vitro and in vivo. However, when it came to the growth of cervical cancer cell lines in vitro, Hiwi was revealed to inhibit the viability of the cervical cancer cell lines, $\mathrm{SiHa}$ (12). The results of the present study did not verify these findings, but the results were consistent with the results of previous studies $(2,11,18)$. This difference may require further investigation.

Cell cycle analysis of the cervical cancer cells was also undertaken in the present study. The results of the present study demonstrated that cell cycle was arrested upon silencing of Hiwi. Additionally, the levels of cyclin A and cyclin D1 proteins, which are regulators of the cell cycle (20), were also decreased following transfection with Hiwi siRNA. This suggests that the cell cycle of cervical cancer cells was arrested at the G1 phase by downregulation of Hiwi. Consistent with the present study, the results of Wang et al (18) also identified that the downregulation of Hiwi was able to induce cell cycle arrest of glioma cells. However, the results of Liu et al (2) demonstrated that the cell cycle of gastric cancer cells was arrested by Hiwi suppression at the G2/M phase. The molecular mechanisms underlying these differences should be investigated further.

The assays investigating the effects of Hiwi downregulation on the proliferation and cell cycle demonstrated that the growth of cervical cancer cells was inhibited by silencing of Hiwi. In addition to the effects on proliferation and cell cycle, Hiwi is also able to affect cell apoptosis. The results from Wang et al (18) demonstrated that Hiwi suppression induced cell apoptosis in glioma cells. Liang et al (11) also reported that cell apoptosis in lung cancer cells was promoted by suppression of Hiwi.

In the present study, the effects of Hiwi downregulation on the epithelial-mesenchymal transition process in cervical cancer cells were also detected. The results of the present study demonstrated that the downregulation of Hiwi was able to increase the level of E-cadherin, and decrease the level of N-cadherin, vimentin and snail, which are hallmarks of epithelial-mesenchymal transition (EMT) (21-25), suggesting that suppression of Hiwi was able to inhibit the EMT process. The results of Wang et al (18) demonstrated that suppression of Hiwi was also able to inhibit the migration and invasion of glioma cells with decreased expression of matrix metalloprotein-2 and matrix metalloprotein-9 which are associatd with degradation of the extracellular matrix, thus contributing to the migration and invasion of cells $(26,27)$. Jiang et al (17) demonstrated that the expression of Hiwi was associated with metastasis to intrahepatic tissue, local lymph nodes and remote organs. Raeisossadati et al (15) also demonstrated that Hiwi expression was associated with tumor invasion depth. Hiwi is also associated with the angiogenesis of cancer (9).

To conclude, in the present study, the effects of Hiwi on the growth and epithelial-mesenchymal transition process of cervical cancer cells was investigated. The results of the present study indicated that the suppression of Hiwi was able to inhibit the growth of cervical cancer cells and arrest the cell cycle. The epithelial-mesenchymal transition was also inhibited by the downregulation of Hiwi. The present study indicates that Hiwi may act as an oncogene in cervical cancer cells, and that it may be a target for novel cervical cancer therapy.

\section{Competing interests}

The authors declare that they have no competing interests.

\section{References}

1. Arbyn M, Castellsagué X, de Sanjosé S, Bruni L, Saraiya M, Bray $\mathrm{F}$ and Ferlay J: Worldwide burden of cervical cancer in 2008. Ann Oncol 22: 2675-2686, 2011.

2. Liu X, Sun Y, Guo J, Ma H, Li J, Dong B, Jin G, Zhang J, Wu J, Meng L and Shou C: Expression of hiwi gene in human gastric cancer was associated with proliferation of cancer cells. Int J Cancer 118: 1922-1929, 2006. 
3. Seto AG, Kingston RE and Lau NC: The coming of age for Piwi proteins. Mol Cell 26: 603-609, 2007.

4. Hutvagner G and Simard MJ: Argonaute proteins: Key players in RNA silencing. Nat Rev Mol Cell Biol 9: 22-32, 2008

5. Sharma AK, Nelson MC, Brandt JE, Wessman M, Mahmud N, Weller KP and Hoffman R: Human CD34(+) stem cells express the hiwi gene, a human homologue of the Drosophila gene piwi. Blood 97: 426-434, 2001.

6. Qiao D, Zeeman AM, Deng W, Looijenga LH and Lin H: Molecular characterization of hiwi, a human member of the piwi gene family whose overexpression is correlated to seminomas. Oncogene 21: 3988-3999, 2002.

7. Grochola LF, Greither T, Taubert H, Möller P, Knippschild U, Udelnow A, Henne-Bruns D and Würl P: The stem cell-associated Hiwi gene in human adenocarcinoma of the pancreas: Expression and risk of tumour-related death. Br J Cancer 99: 1083-1088, 2008.

8. Taubert H, Greither T, Kaushal D, Würl P, Bache M, Bartel F, Kehlen A, Lautenschläger C, Harris L, Kraemer K, et al: Expression of the stem cell self-renewal gene Hiwi and risk of tumour-related death in patients with soft-tissue sarcoma. Oncogene 26: 1098-1100, 2007.

9. Li S, Meng L, Zhu C, Wu L, Bai X, Wei J, Lu Y, Zhou J and Ma D: The universal overexpression of a cancer testis antigen hiwi is associated with cancer angiogenesis. Oncol Rep 23: 1063-1068, 2010.

10. He W, Wang Z, Wang Q, Fan Q, Shou C, Wang J, Giercksky KE, Nesland JM and Suo Z: Expression of HIWI in human esophageal squamous cell carcinoma is significantly associated with poorer prognosis. BMC Cancer 9: 426, 2009

11. Liang D, Fang Z, Dong M, Liang C, Xing C, Zhao J and Yang Y: Effect of RNA interference-related HiWi gene expression on the proliferation and apoptosis of lung cancer stem cells. Oncol Lett 4: 146-150, 2012.

12. Liu W, Gao Q, Chen K, Xue X, Li M, Chen Q, Zhu G and Gao Y: Hiwi facilitates chemoresistance as a cancer stem cell marker in cervical cancer. Oncol Rep 32: 1853-1860, 2014.

13. Liu WK, Jiang XY and Zhang ZX: Expression of PSCA, PIWIL1 and TBX2 and its correlation with HPV16 infection in formalin-fixed, paraffin-embedded cervical squamous cell carcinoma specimens. Arch Virol 155: 657-663, 2010.

14. Livak KJ and Schmittgen TD: Analysis of relative gene expression data using real-time quantitative PCR and the 2(-Delta Delta C(T)) method. Methods 25: 402-408, 2001.
15. Raeisossadati R, Abbaszadegan MR, Moghbeli M, Tavassoli A, Kihara AH and Forghanifard MM: Aberrant expression of DPPA2 and HIWI genes in colorectal cancer and their impacts on poor prognosis. Tumour Biol 35: 5299-5305, 2014.

16. Zeng Y, Qu LK, Meng L, Liu CY, Dong B, Xing XF, Wu J and Shou CC: HIWI expression profile in cancer cells and its prognostic value for patients with colorectal cancer. Chin Med J (Engl) 124: 2144-2149, 2011.

17. Jiang J, Zhang H, Tang Q, Hao B and Shi R: Expression of HIWI in human hepatocellular carcinoma. Cell Biochem Biophys 61: $53-58,2011$

18. Wang X, Tong X, Gao H, Yan X, Xu X, Sun S, Wang Q and Wang J: Silencing HIWI suppresses the growth, invasion and migration of glioma cells. Int J Oncol 45: 2385-2392, 2014.

19. Taubert H, Würl P, Greither T, Kappler M, Bache M, Bartel F, Kehlen A, Lautenschläger C, Harris LC, Kaushal D, et al: Stem cell-associated genes are extremely poor prognostic factors for soft-tissue sarcoma patients. Oncogene 26: 7170-7174, 2007.

20. Lim S and Kaldis P: Cdks, cyclins and CKIs: Roles beyond cell cycle regulation. Development 140: 3079-3093, 2013.

21. Lin Y, Dong C and Zhou BP: Epigenetic regulation of EMT: The Snail story. Curr Pharm Des 20: 1698-1705, 2014.

22. Schmalhofer O, Brabletz S and Brabletz T: E-cadherin, beta-catenin, and ZEB1 in malignant progression of cancer. Cancer Metastasis Rev 28: 151-166, 2009.

23. Radice GL: N-cadherin-mediated adhesion and signaling from development to disease: Lessons from mice. Prog Mol Biol Transl Sci 116: 263-289, 2013.

24. Przybyla L, Muncie JM and Weaver VM: Mechanical control of epithelial-to-mesenchymal transitions in development and cancer. Annu Rev Cell Dev Biol 32: 527-554, 2016.

25. Kokkinos MI, Wafai R, Wong MK, Newgreen DF, Thompson EW and Waltham M: Vimentin and epithelial-mesenchymal transition in human breast cancer-observations in vitro and in vivo. Cells Tissues Organs 185: 191-203, 2007.

26. Webb AH, Gao BT, Goldsmith ZK, Irvine AS, Saleh N, Lee RP, Lendermon JB, Bheemreddy R, Zhang Q, Brennan RC, et al: Inhibition of MMP-2 and MMP-9 decreases cellular migration, and angiogenesis in in vitro models of retinoblastoma. BMC Cancer 17: 434, 2017.

27. Itoh $\mathrm{Y}$ and Nagase $\mathrm{H}$ : Matrix metalloproteinases in cancer. Essays Biochem 38: 21-36, 2002. 